\title{
Rhizosphere competence of native Rhizobium rhizogenes strain and its use in management of crown gall
}

\author{
Randeep Singh $^{1}$, Aditi Sharma ${ }^{1}$ and A. K. Gupta ${ }^{1}$ \\ ${ }^{1}$ Department of Plant Pathology, Dr. Y. S. Parmar University of Horticulture and Forestry, Nauni, Solan- 173230 , \\ (Himachal Pradesh), INDIA \\ *Corresponding author. E-mail: aditi.bhardwaj650@gmail.com \\ Received: September 8, 2016; Revised received: April 8, 2017; Accepted: August 20, 2017
}

\begin{abstract}
Native Rhizobium rhizogenes strain UHFBA-212 [141/1A (NCBI: KC488174)]was isolated from rhizosphere soil of peach nursery plant of wild peach collected from Himachal Pradesh. In addition to this, 159 isolates were also collected and were screened in vitro for their biocontrol potential against Agrobacterium tumefaciens. Out of these strain, UHFBA-212 showed maximum zone of inhibition i.e. 4.16 and $3.57 \mathrm{~cm}$ without and after exposure to chloroform against C58.Sequence analysis (16SrDNA) of the strain showed nucleotide homology similar to Rhizobium sp. Amplification of total genomic DNA of the strain with Vir D2 andipt primers didn't showed amplification with these virulence genes suggesting the absence of tumorigenic factors. In the field conditions, maximum population $\left(329.33 \times 10^{6} \mathrm{cfu} / \mathrm{g}\right.$ of soil) was observed in antibiotic resistant mutant of $R$. rhizogenes strain K84 applied on cherry rootstock Colt followed by $285.33\left(\times 10^{6}\right) \mathrm{cfu} / \mathrm{g}$ of soil in UHFBA-212 after 9 months at the time of uprooting of plants when applied alone as root dip. Minimum incidence of crown gall (2.00\%) was observed in strain UHFBA212 co inoculated with strain C58 as seed treatment on behmi seeds. The data on population indices in rhizosphere and incidence of crown gall further suggested that for better management of disease $R$. Rhizogenes isolates should be either equal or more in population than that of $A$. tumefaciens isolates. Strain UHFBA-212 controls crown gall as effectively as strain K84 and can be exploited against tumorigenic isolates under field conditions.
\end{abstract}

Keywords: Colonization, Disease incidence, Resistant, Rhizobium rhizogenes

\section{INTRODUCTION}

The area under stone fruit cultivation has shown an upward swing from the last few years in Himachal Pradesh. The natural genetic engineer Agrobacterium tumefaciens (Smith and Townsend, 1907) Conn. (1942) is a ubiquitous soil inhabitant and causes crown gall of various stone and pome fruits nurseries (Bouzar et al., 1991 and Thakur et al., 2007). During infection process the T-DNA ofAgrobacterium tumefaciens gets integrated in host genome, resulting in over expression of the biosynthesis of phytohormones such as auxins and cytokinins and other low molecular weight opines, leading to abnormal cell division and proliferation (Zambryski, 1998). The galled seedlings become unfit for production and need to be disposed off. These problems have resulted in lower productivity and increased susceptibility of infected plants to biotic and abiotic stresses.

The pathogen belongs to family Rhizobiaceae and taxonomically designated as Agrobacterium tumefaciens for the tumorigenic isolates and non pathogenic strains as A. radiobacter. Sawada et al. (1993) proposed $A$. radiobacter in place of $A$. tumefaciens to include both pathogenic and non pathogenicA. tumefaciens. Further different agrobacterial genus (A. larry- moorei, A. radiobacter, A. tumefaciens, A. vitis, A. rubi and $A$. rhizogenes) were amalgamated in a single genus 'Rhizobium' (Young et al., 2001).On the basis of $16 \mathrm{~S}$ rRNA sequencing the pathogen showed unique phenotypic genetic circumscriptions and was found similar to Allorhizobium and Rhizobium (Costechareyre et al, 2010;Lindstrom and Young 2011). Based on the multilocus sequence analysis (MLSA) of protein coding housekeeping genes among different agrobacterial taxa the taxonomic nomenclature of Agrobacterium as Rhizobium rhizogenes was considered as proper name (Mousavi et al., 2014).

Successful biological control of crown gall by using $R$. rhizogenes strain $\mathrm{K} 84$ has been reported worldwide after its discovery by Kerr (1972) from Australia. However, this particular strain is not commercially available in India nor as effective as reported in other countries. In spite of the success of K84, some potential problems can arise from its application (Moore and Canfield, 1996). Under field conditions the biocontrol efficiency of strain K84 fails due to the conjugal transfer of agrocin plasmid (pAgK84), resulting in breakdown of the biocontrol capacity, because the recipient becomes resistant to agrocin 84 thus remaining pathogenic (Penalver and Lopez, 1999; Stockwell et al., 1996, Raio et al., 2009). 
Therefore, a search for other antagonists for controlling crown gall is currently under way all over the world (Raio et al., 2009; Gupta et al., 2010; Kawaguchi, 2014; Kawaguchi, 2015). Thus, in the present work we explored the efficacy of native agrobacterial strain for its potential to control A. tumefaciens in vitro and in planta and also determined the comparative colonization efficacies and persistence of $R$. rhizogenes (native strainUHFBA-212 and standard strain K84) and A. tumefaciens isolates (native isolate $\mathrm{I}_{1}$ and C58) in the rhizosphere soil of stone fruit plants.

\section{MATERIALS AND METHODS}

Samples collection and isolation of Rhizobium isolates from infected seedlings: Actively growing galls on diseased peach plants were collected in sterilized polyethylene bags from nurseries of different locations of Himachal Pradesh (Fig.1) in the month of October-November. The fresh galls were detached carefully and washed in running water to remove soil. Small sections of living tissues chopped with a sterilized scalpel and immersed in sterilized distilled water and were left standing for $30 \mathrm{~min}$ at room temperature. A loopful of the suspension was streaked on two selective media namely Yeast Extract Mannitol Agar (YEMA) and D1 medium and plates were incubated for 2-3 days at $25 \pm 1^{\circ} \mathrm{C}$ (Murugesan et al., 2010). The colonies that were representative of Agrobacterium were restreaked on D1 medium for further purification. The purified colonies were then stored at $4{ }^{\circ} \mathrm{C}$ on YEMA medium supplemented with $0.5 \% \mathrm{CaCO}_{3}$.

In vitro evaluation for antagonism and agrocin production: The isolates were evaluated for their antagonism against $A$. tumefaciens strain C58 as per method described by New and Kerr (1972). Antagonistic isolates were spot inoculated on mannitol glutamate agar medium supplemented with biotin $(2 \mu \mathrm{g} / \mathrm{ml})$ and the plates were incubated for 3 days at $27^{\circ} \mathrm{C}$ in a BOD incubator. In one set, the test antagonist was killed by chloroform and plates were then lightly misted with A. tumefaciens. In second set, plates were lightly misted with A. tumefaciens without killing the test antagonist. The presence of zone of inhibition (diameter measured in $\mathrm{cm}$ ) in plates without exposure to chloroform, indicated that isolate was having antagonistic activity against $A$. tumefaciens and zone of inhibition in the plates exposed to chloroform suggested production of bacteriocin.

In vitro evaluation for inhibition of gall developments by antagonistic isolate (s) on tomato plants: Tomato plants var. Solan Gola were wounded by causing $3 \mathrm{~mm}$ deep injuries at crown, middle and tip portion of stem with the help of sterilized blunt steel rod of $2 \mathrm{~mm}$ diameter, with the help of sterilized micropipette, $0.004 \mathrm{ml}$ of test



Fig. 1. Location map indicating the different sampling sites in Himachal Pradesh.

antagonist suspension $\left(10^{8} \mathrm{CFU} / \mathrm{ml}\right)$ was inoculated in each wound. Wounds were then wrapped with sterilized non-absorbent cotton. After $24 \mathrm{~h}$, cotton was removed from the wounds and the pathogenic strain (A.tumefaciens strain C58) was applied $\left(0.004 \mathrm{ml}\right.$ having $\left.10^{8} \mathrm{CFU} / \mathrm{ml}\right)$ to the same wounds. The wounds were again wrapped with fresh sterilized non-absorbent cotton. Each test antagonist was again inoculated on nine tomato plants representing three replication (three plants/ replication). Plants inoculated with only A.tumefaciens (C58, $\mathrm{I}_{1}$ and $\mathrm{I}_{2}$ ) and R.rhizogenes K84 served as positive and negative control, respectively. The observation on gall development on tomato seedlings were made after four weeks of inoculation (New and Kerr, 1972).

Detection of virD2 and ipt genes in antagonistic strains: Genomic DNA of Rhizobium rhizogenes strain (UHFBA-212 and K84) and A.tumefaciens $\left(\mathrm{C} 58\right.$, andI $\left._{1}\right)$ was isolated using total DNA isolation Kit (real genomic isolation kit as per manufacturer's instructions). The isolated DNA was finally suspended in $100 \mu 1$ of elution buffer and quantified on one per cent agarose gel.

PCR reaction mixtures $(50 \mu \mathrm{l})$ contained primer oligonucleotides at $0.4 \mu \mathrm{M}$ each, deoxynucleotide triphosphates at $200 \mu \mathrm{M}$ each, $1 \mathrm{U}$ of thermostable DNA polymerase (Perkin-Elmer [Taq] or Epicenter technologies [Tft], reaction cocktail supplied by the manufacturer (Perkin- Elmer, $10 \mathrm{mM}$ Tris [pH 8.3 at $25^{\circ} \mathrm{C}$ ], $50 \mathrm{mMKCl}, 1.5 \mathrm{mM} \mathrm{MgCl}_{2}, 0.001 \%$ gelatin [sigma G2500]; Epicenter, 50mM Tris [pH 9.0 at $25^{\circ} \mathrm{C}$ ], $20 \mathrm{mM}$ ammonium sulphate, $1.5 \mathrm{mM} \mathrm{MgCl} 2$ ), and 50 to $250 \mathrm{ng}$ of purified template DNA. Amplifi- 
cation was initiated by incubation at $94^{\circ} \mathrm{C}$ for $1 \mathrm{~min}$ followed by 40 cycles at 94,50 and $72^{\circ} \mathrm{C}$ for $1 \mathrm{~min}$ at each temperature.

PCR based virulence assay was carried out based on virD2 and ipt genes as previously described by Haas et al. (1995). Amplification of virD2 gene was carried out using, one sense-strand oligonucleotide, primer A, and two antisense-strand oligonucleotides, primer C' and primer E' (Table 1). These primers were used in two different pairs to produce PCR products of $338 \mathrm{bp}$ (A-E') and $224 \mathrm{bp}$ (A-C'). The ipt gene of 427bp was amplified using primers sense-strand primer, CYT, and antisense-strand primer, CYT' (Table 1).

Development of mutants of Rhizobium rhizogenes and $A$. tumefaciens: The most effective native Rhizobium rhizogenes strainUHFBA212 along with standard strain K84, A. tumefaciens isolate $\mathrm{I}_{1}$ and $\mathrm{C} 58$ were selected for further studies. Rhizobium rhizogenes (UHFBA-212 and K84) resistant to rifampicin (2500ppm) and A. tumefaciens (C58 and $\mathrm{I}_{1}$ )resistant to streptomycin (2500ppm) were developed by repeated culturing in YEM broth amended with desired concentration of antibiotics (upto 100 generations with no selection pressure) as per method described by Moore and Allen (1977). The stability of mutants was evaluated after growth at $2500 \mathrm{ppm}$ concentrations of antibiotics for over 100 generations by streaking on antibiotic amended medium. Antibiotic resistant mutants were also compared with parent strain (s) for agrocin production i.e. in strain K84 and UHFBA-212 and for pathogenicity of A. tumefaciens strain $\mathrm{C} 58$ and $\mathrm{I}_{1}$ by artificial inoculation on 4 weeks old potted tomato plants.

Application of resistant mutants as seed and root dip treatment: The antibiotic resistant mutants of Rhizobium rhizogenes and A. tumefaciens were evaluated as seed treatment on bitter almond and root dip treatment on cherry rootstock Colt as per method described by Vicedo et al. (1993) in the followings sets:

i) Seed treatment/root dip with $R$. rhizogenes strains.

ii) Seed treatment/root dip with A. tumefaciens isolates.

iii) Co-inoculation of seed /roots with $R$. rhizogenes and A. tumefaciens.

iv) Un-inoculated seeds/roots dipped in non chlorinated water to serve as control.

Growth of one antibiotic resistant bacterial culture (late-exponential-phase cells adjusted turbidometrically to densities of approximately $5 \times 10^{8} \mathrm{CFU} / \mathrm{ml}$ ) was scrapped in four litre non chlorinated water and dissolved by stirring gradually with the help of sterilized stick. Seeds of bitter almond and roots of cherry rootstock Colt were soaked in the antibiotic resistant bacterial suspension for half an hour and later shade dried for 1 hour before planting in the field. In control, no bacterial culture was used (seeds and roots were dipped in non chlorinated water). Later, the seeds were sown in the field beds in randomized block design layout in 42 beds. In each bed 15 plants of cherry rootstock Colt were planted and 40 seeds of bitter almond per bed were sown with a row to row distance of $25 \mathrm{~cm}$ and plant to plant distance of $20 \mathrm{~cm}$ in $1 \mathrm{~m}^{2}$ plot size. Initial populations of bacterial culture used for seed and root dip treatments are listed in Table 2.

Colonization of inoculated seeds / roots by antibiotics resistant mutants vis- a-vis incidence of crown gall: The population of antibiotics resistant mutants both from the plants raised from inoculated and un - inoculated bitter almond seeds and root dip treated Colt suckers were estimated from seed surface at the time of sowing and roots of treated plants as per method described by Gupta et al. (2010) after 1, 3, 6 and at the time of uprooting of the plants after nine months. The colony forming units $/ \mathrm{ml}$ was determined by serial dilution method on rifampin and streptomycin supplemented YEMA medium at $2500 \mathrm{ppm}$ after incubation of plates at temp of $25 \pm 1^{\circ} \mathrm{C}$ in a BOD for 3 days. At the time of uprooting of plants, incidence of crown gall was also computed by following formula

Disease incidence $(\%)=$ Number of diseased plants $/$ Total number of plants examined $\times 100$

Sequence homology confirmation of Rhizobium rhizogenes strain UHFBA-212 by 16S rDNA: Genomic DNA of UHFBA-212 was isolated by growing it at $25^{\circ} \mathrm{C}$ in YEMA broth at $200 \mathrm{rpm}$. The cells were harvested and processed for DNA isolation, using total DNA isolation kit (GeNeiGenPro isolation kit as per manufacturer's instructions). The isolated DNA was suspended in $100 \mu \mathrm{l}$ of elution buffer and quantified on 1 per cent agarose gel. PCR reaction was carried out in $20 \mu 1$ reaction containing $50 \mathrm{ng}$ of template DNA, 20 picomolar of each primers F667-pA-res and F668-pHres, $0.2 \mathrm{mM}$ of dNTP's and $1 \mathrm{U}$ Taq Polymerase (MP Biomedicals, USA) in $1 \times$ PCR buffer. The PCR products were analyzed by 1 per cent agarose gel electrophoresis in TEB buffer ( $90 \mathrm{mM}$ Tris base, $2 \mathrm{mM}$ EDTA, $90 \mathrm{mM}$ boric acid [pH 8.3]) with500 $\mathrm{ng}$ of ethidium bromide per ml. PCR product was eluted and purified using PCR purification kit (Real Genomic as per manufacturer's instructions) and sequenced thereafter. The sequences were aligned with those from GenBank database. Phylogenetic trees were inferred using the neighbour-joining (NJ) method. Bootstrap analyses were calculated based on 1000 replications (Felsenstein, 1985). The gene sequence (16S rDNA) determined in this study has been deposited in the NCBI database, and the GenBank accession numberis KC488174. Table 3lists the primers used in this study.

Statistical analysis: Experimental data was analysed 
using standard analysis of variance (ANOVA) followed by Duncan's multiple comparison tests $(p \leq 0.05)$.

\section{RESULTS AND DISCUSSION}

Biological control of bacterial plant diseases is of increasing interest and importance. Crown gall caused by Agrobacterium tumefaciensis one of the great challenge and the main limiting factor in raising quality nursery plants (Gupta et al., 2005). Various integrated disease management practices have been tested world over (Kapshuk, 1933; Escobar and Dandekar, 2003; Pulawska, 2010) and were found ineffective. Rhizobium rhizogenes strain K-84 and it's genetically engineered derivative K1026, were found most effective in controlling the crown gall in stone fruit nurseries (Kerr, 1972; Kerr and Htay, 1974). Later, it was rewgnized that some biological control activities are independent of agrocin production as some of $\mathrm{pAgK} 84$ variants of strain K-84 were also able to reduce the gall size. Hence, other mechanisms such as rhizosphere colonization, blockage and binding to infection sites, production of antibiotics etc. also operate depending upon the genetic makeup of antagonist (Lippincott et al., 1977;Gupta et al., 2010). Therefore, the present investigations were envisaged to find other agrocin producing isolates, exhibiting rhizosphere persistence and detracting incidence of crown gall in



Fig. 2. PCR based amplification of Rhizobium rhizogenes and Agrobacterium tumefaciens DNA templates with vir D2 and ipt primers.

L: Ladder (100bp); 1,5,9: K84; 2,6,10: C58; 3,7,11: $\mathrm{I}_{1}$; 4,8,12: UHFBA-212; 13: Control 1-4: vir D2 primers A-E', 5 -8: vir D2 primers A-C', 9-12: iptprimers CYT-CYT' comparison to standard strain K-84.

In vitro selection of antagonistic isolates: Total 159 isolates of Agrobacterium were collected from rhizosphere soil from different locations of Himachal Pradesh. In addition to this, $R$. rhizogenes strain K84 as standard strain was also taken in present studies. In vitro evaluation of different isolatesagainst pathogenic A. tumefaciens with or without exposure to chloroform vapours revealed that they were able to inhibit the growth of A. tumefaciens (Table 4). Therefore, these isolates were considered as agrocinogenic. Maximum zone of inhibition $(4.16 \mathrm{~cm})$ without exposure was observed in UHFBA-212, whereas $3.90 \mathrm{~cm}$ maximum zone of inhibition was observed in Sam -21 (4) after exposure to chloroform followed by $3.57 \mathrm{~cm}$ in the UHFBA-212. The native isolate $R$. rhizogenes UHFBA -212 was superior to strain K-84 of Kerr (1972).Wang et al. (2003) reported that an antibacterial compound named Ar26 produced by non-pathogenic Rhizobiumvitis strain E26 inhibited the growth of some Ti strains of Rhizobium on culture plates. There are many reports where native strains are significantly controlling the crown gall of apple, stone fruits and grapewine (Kawaguchi, 2008;Gupta et al., 2010; Kawaguchi, 2013).

Evaluation of antagonistic isolate(s) for their antagonism against $A$. tumefaciens for gall development on potted tomato plants: In order to find out the effective biocontrol agent, different test antagonist (s) isolated from rhizosphere soil were tested against $A$. tumefaciensstrain C58for their antagonistic activity by cross inoculation method on tomato plants. Nonpathogenic isolates when cross inoculated against pathogenic A. tumefaciensisolate is strain C58 on tomato plants showed varied reactions. Antagonisticisolates viz., UHFBA-13, UHFBA-14, UHFBA-15, UHFBA-16, UHFBA-17, UHFBA-18, UHFBA-19, UHFBA-20, UHFBA-21, UHFBA-40, UHFBA-41, UHFBA-42, UHFBA-43, UHFBA-44, UHFBA-45, UHFBA-46, UHFBA-47, UHFBA-48, K84 and UHFBA212 completely inhibited the gall formation on indica-

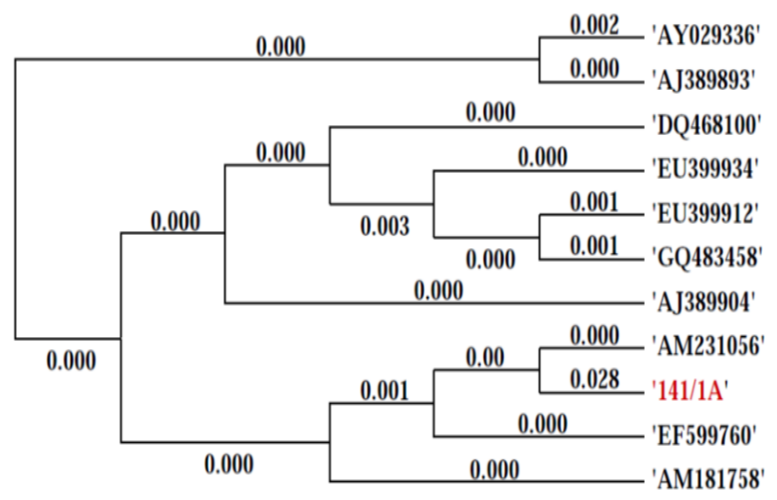

Fig. 3. Neighbour-joining phylogenetic dendrogram based on $16 \mathrm{~S}$ rDNA sequences showing relationships between different isolates. 
Table 1. Oligonucleotide primers and PCR cycling conditions used in the study.

\begin{tabular}{|c|c|c|c|c|}
\hline Gene name & Primer & Sequence 5'-3' & Anneal. temp. $\left({ }^{\circ} \mathrm{C}\right)$ & Reference \\
\hline \multirow[t]{3}{*}{ virD2 } & $\mathrm{A}$ & ATGCCCGATCGA GCT CAA GT & 52 & \\
\hline & E' & CCTGACCCAAACATCTCGGCTGCCCA & & Haas et al.,1995 \\
\hline & $C^{\prime}$ & TCGTCTGGCTGACTTTCGTCATAA & & \\
\hline \multirow[t]{2}{*}{ ipt } & CYT & GATCG(G/C)GTCCAATG(C/T)TGT & 55 & \\
\hline & CYT' & GATATCCATCGATC(T/C)CTT & & \\
\hline
\end{tabular}

Table 2. Initial population of bacterial culture used for seed and root dip treatments.

\begin{tabular}{ll}
\hline Bacterial culture & CFU $\times \mathbf{1 0}^{\mathbf{6}}$ \\
\hline K84 & 182 \\
UHFBA-212 & 180 \\
$\mathrm{I}_{1}$ & 184 \\
C58 & 182 \\
\hline
\end{tabular}

tor tomato plants.Agrobacterium tumefaciensstrain C58 and native isolate $\mathrm{I}_{2}$ from Bajaura resulted in 7.33 and 4.00 number of wounds showing galls respectively (Table 5). Similar results of gall development on tomato seedlings were observed by different workers (Kerr, 1969); New and Kerr, 1972; Jindal and Sharma, 1988; and Gupta et al., 2005).

Detection of virD2 and ipt genes in antagonistic strains: Total genomic DNA of Rhizobium rhizogenes UHFBA-212, strain K84and pathogenic isolates was amplified with virulence vir D2 and ipt gene specific primers. There was no amplification in genomic DNA of Rhizobium rhizogenes UHFBA-212 and strain K84, suggesting absence of virulence genes. Agrobacterium tumefaciens $\left(\mathrm{C} 58\right.$ and $\mathrm{I}_{1}$ ) isolates resulted in 338, 224 and 427 bp product with vir D2 AE, AC and iptpimer (Fig. 2).

Colonization of inoculated seeds/roots by antibiotic resistant mutants: Colonization of root surface by $R$. rhizogenes isolates is one of the most important factor contributing to biocontrol. The antibiotic resistant mutants of $R$. rhizogenes and A. tumefaciens were used for enumeration of their population from the day of sowing till the uprooting of nursery plants after treating roots of cherry rootstock Colt and bitter almond seeds.

Colonization on root dip (RD) treated cherry rootstock Colt plants: Maximum population $(269.67 \times$ $10^{6} \mathrm{cfu} / \mathrm{g}$ of soil) was recovered in native $R$. rhizogenes isolate UHFBA-212 followed by $207.00 \times 10^{6} \mathrm{cfu} / \mathrm{g}$ of soil in K84 applied as root dip on cherry rootstock Colt. UHFBA-212 co-inoculated with A. tumefaciens $\mathrm{I}_{1}$ as root dip gave $145.00 \times 10^{6} \mathrm{cfu} / \mathrm{g}$ and it was statistically at par of $\mathrm{C} 58$ population $\left(143.31 \times 10^{6} \mathrm{cfu} / \mathrm{g}\right)$ when $A$. radiobacter $\mathrm{K} 84$ was co inoculated with $\mathrm{C} 58$ after one month. After a period of three and six months population of both $R$. rhizogenes and A. tumefaciens were either nil or negligible. Maximum population $\left(11.33 \times 10^{6} \mathrm{cfu} / \mathrm{g}\right)$ was observed for A. tumefaciens $\mathrm{I}_{1}$ co inoculated with UHFBA-212 after three months. Population after six months $\left(23.00 \times 10^{6} \mathrm{cfu} / \mathrm{g}\right)$ was observed for C58 as root dip treatment followed by $\left(15.00 \times 10^{6} \mathrm{cfu} / \mathrm{g}\right)$ for A. tumefaciens $\mathrm{I}_{1}$. No population could be observed for most of the treatments after six months (Table 6).

There was an increase in population at the time of uprooting of plants i.e. ninth month. Maximum population $\left(329.33 \times 10^{6} \mathrm{cfu} / \mathrm{g}\right)$ was observed for K84 followed by $285.33 \times 10^{6} \mathrm{cfu} / \mathrm{g}$ for UHFBA-212 applied alone. Minimum population $\left(9.33 \times 10^{6} \mathrm{cfu} / \mathrm{g}\right)$ was observed for A. tumefaciens $\mathrm{I}_{1}$ as root dip treatment on cherry rootstock Colt. Untreated cherry rootstock Colt plant showed no population up to the time of uprooting of plants. Mean values of three and six month periods were statistically at par with each other. The mean values showed that root dip treated K84 and UHFBA212 are statistically at par in Duncan's multiple comparison tests $(p \leq 0.05)$.

Colonization on seed treated (ST) bitter almond plants: Maximum population $212.89 \times 10^{6} / \mathrm{g}$ was observed for seed treated UHFBA-212 was co inoculated with C58 followed by $198.67 \times 10^{6} / \mathrm{g}$ for K84 when co inoculated with $A$. tumefaciens $\mathrm{I}_{1}$ after one month on bitter almond. Minimum population of UHFBA-212 $\left(20.28 \times 10^{6} / \mathrm{g}\right)$ was observed in seed treated bitter almond plants. After three and six months, the population decreased below the range of detectable limits. Maximum viable counts $\left(6.33 \times 10^{6} / \mathrm{g}\right)$ were observed for UHFBA-212 seed treated bitter almond plants after three months followed by $4.67 \times 10^{6} / \mathrm{g}$ in $\mathrm{K} 84$. After six months no viable counts were observed for K84 and UHFBA-212. Maximum population $17 \times 10^{6} / \mathrm{g}$ was observed for C58 and it was statistically at par with $\left(16 \times 10^{6} / \mathrm{g}\right)$ in $A$. tumefaciens $\mathrm{I}_{1}$ as seed treatment. At the time of uprooting maximum viable counts $(311.33$ $\mathrm{x} 10^{6} / \mathrm{g}$ ) was observed for K84 followed by 193.67 $\mathrm{x} 10^{6} \% \mathrm{~g}$ in UHFBA-212 seed treated bitter almond plants. Minimum population $87 \times 10^{6} / \mathrm{g}$ was observed for UHFBA-212 when co inoculated with C58. Mean values for treatments showed maximum population

Table 3. Primers used for $16 \mathrm{SrDNA}$ sequencing.

\begin{tabular}{lllll}
\hline Gene name & Primer & Sequence 5'-3' & Anneal.temp. $\left({ }^{\circ} \mathrm{C}\right)$ & Reference \\
& & & & \\
\hline 16S rDNA & F667-pA-res & AGAGTTTGATCCTGGTGAG & 57 & Bruce et al., 1992 \\
& F668-pH-res & AAGGAGGTGATCCAGCCGCA & & \\
\hline
\end{tabular}


Table 4. In vitro evaluation of Agrobacterium radiobacter isolate (s) for antagonism and detection of agrocin production after exposure to chloroform.

\begin{tabular}{lcc}
\hline \multirow{2}{*}{ Isolate (S) } & \multicolumn{2}{c}{ Zone of inhibition (cm) } \\
\cline { 2 - 3 } & $\begin{array}{c}\text { Without exposure to } \\
\text { chloroform vapours }\end{array}$ & $\begin{array}{c}\text { After exposure to } \\
\text { chloroform vapours }\end{array}$ \\
\hline UHFBA-14 & 2.60 & 3.07 \\
UHFBA-15 & 3.26 & 1.89 \\
UHFBA-16 & 2.90 & 2.07 \\
UHFBA-17 & 1.54 & 1.63 \\
UHFBA-18 & 1.50 & 2.16 \\
UHFBA-21 & 1.23 & 2.09 \\
UHFBA-42 & 2.45 & 2.76 \\
UHFBA-43 & 1.54 & 2.33 \\
UHFBA-44 & 3.40 & 1.98 \\
UHFBA-45 & 3.00 & 2.78 \\
UHFBA-46 & 1.54 & 2.47 \\
UHFBA-47 & 2.76 & 2.99 \\
UHFBA-48 & 1.74 & 3.04 \\
Sam 21(4) & 2.78 & 3.90 \\
UHFBA-212 & 4.16 & 3.57 \\
K84 & 2.92 & 1.21 \\
\hline
\end{tabular}

$\left(111.58 \times 10^{6} / \mathrm{g}\right)$ in $\mathrm{K} 84$ followed by $89.92 \times 10^{6} / \mathrm{g}$ in K84 co-inoculated with $A$. tumefaciens $\mathrm{I}_{1}$. Mean values for months showed maximum viable counts i.e. 137.37 $\mathrm{x} 10^{6} / \mathrm{g}$ after nine months followed by $109.17 \times 10^{6} / \mathrm{g}$ after one month while three and six months mean were statistically at par in Duncan's multiple comparison test (Table 7).

Population densities of agrobacteria were minimum or almost nil during the growth period which suggest that these bacteria might have dispersed from the treated sites to nearby sites, thereby these were not within the detectable limits of routinely used dilution plate method. The same observations were also observed by Raio et al., (1997). As most of studies have been done on strain K84 no information available for other isolates. The population sizes of native $R$. rhizogenes strain UHFBA-212 and K84 were similar to those reported for other rhizospheric bacteria (Bull et al., 1991; Gross, 1988 and Loper et al., 1985). Penalver and Lopez (1999) suggested that the ability of strain K84 to colonize and persist on roots is important in the biological control process. Maximum viable counts were observed for strain $\mathrm{K} 84$ at the time of uprooting in cherry rootstock colt and bitter almond plants followed by native strain UHFBA-212. The population of $R$. rhizogenes isolate UHFBA-212 with that of A. tumefaciens $\mathrm{I}_{1}$ when it was co inoculated and applied as root dip and soil drench, indicated that both $R$. rhizogenes and $A$. tumefaciens isolates coexist in the rhizosphere soil and if the population of antagonist become low, it give chance to pathogen to cause disease. Similar re-

Table 5. In vitro evaluation of antagonistic isolates for inhibition of gall development on potted tomato plants

\begin{tabular}{|c|c|c|c|c|}
\hline Test antagonist & $\begin{array}{c}\text { Number of wounds } \\
\text { inoculated }\end{array}$ & $\begin{array}{c}\text { Number of wounds } \\
\text { showing galls }\end{array}$ & $\begin{array}{l}\text { Number of galls } \\
\text { per wounds }\end{array}$ & $\begin{array}{c}\text { Gall size } \\
(\mathrm{cm})\end{array}$ \\
\hline \multicolumn{5}{|l|}{ Non pathogenic } \\
\hline UHFBA-13 & 9.00 & 0.00 & 0.00 & 0.00 \\
\hline UHFBA-14 & 9.00 & 0.00 & 0.00 & 0.00 \\
\hline UHFBA-15 & 9.00 & 0.00 & 0.00 & 0.00 \\
\hline UHFBA-16 & 9.00 & 0.00 & 0.00 & 0.00 \\
\hline UHFBA-17 & 9.00 & 0.00 & 0.00 & 0.00 \\
\hline UHFBA-18 & 9.00 & 0.00 & 0.00 & 0.00 \\
\hline UHFBA-19 & 9.00 & 1.00 & 0.12 & 0.73 \\
\hline UHFBA-20 & 9.00 & 0.00 & 0.00 & 0.00 \\
\hline UHFBA-21 & 9.00 & 0.00 & 0.00 & 0.00 \\
\hline UHFBA-40 & 9.00 & 0.00 & 0.00 & 0.00 \\
\hline UHFBA-41 & 9.00 & 0.00 & 0.00 & 0.00 \\
\hline UHFBA-42 & 9.00 & 0.00 & 0.00 & 0.00 \\
\hline UHFBA-43 & 9.00 & 0.00 & 0.00 & 0.00 \\
\hline UHFBA-44 & 9.00 & 0.00 & 0.00 & 0.00 \\
\hline UHFBA-45 & 9.00 & 0.00 & 0.00 & 0.00 \\
\hline UHFBA-46 & 9.00 & 0.00 & 0.00 & 0.00 \\
\hline UHFBA-47 & 9.00 & 0.00 & 0.00 & 0.00 \\
\hline UHFBA-48 & 9.00 & 0.00 & 0.00 & 0.00 \\
\hline UHFBA-212 & 9.00 & 0.00 & 0.00 & 0.00 \\
\hline K84 & 9.00 & 0.00 & 0.00 & 0.00 \\
\hline \multicolumn{5}{|l|}{ Pathogenic } \\
\hline Agrobacterium tumefaciensC58 & 9.00 & 7.33 & 1.81 & 3.76 \\
\hline Agrobacterium tumefaciens $\mathrm{I}_{1}$ & 9.00 & 7.67 & 2.63 & 4.43 \\
\hline Agrobacterium tumefaciens $\mathrm{I}_{2}$ & 9.00 & 4.00 & 1.04 & 1.93 \\
\hline Control & 9.00 & 0.00 & 0.00 & 0.00 \\
\hline Mean & 9.00 & 0.83 & 0.23 & 0.45 \\
\hline
\end{tabular}


Table 6. Colonization of Rhizobium radiobacter and Agrobacterium tumefaciens isolate(s) on root dip (RD) treated cherry rootstock Colt plants.

\begin{tabular}{|c|c|c|c|c|c|c|}
\hline \multirow{2}{*}{\multicolumn{2}{|c|}{ Treatments }} & \multicolumn{5}{|c|}{$\begin{array}{c}\text { Population }\left\{\mathrm{CFU}\left(\mathrm{x10}^{6} / \mathrm{g}\right) \text { of rhizospheric soil after }\right. \\
\text { period of }\}\end{array}$} \\
\hline & & $\begin{array}{c}\text { One } \\
\text { Month }\end{array}$ & $\begin{array}{l}\text { Three } \\
\text { month }\end{array}$ & $\begin{array}{c}\text { Six } \\
\text { month }\end{array}$ & $\begin{array}{c}\text { Nine } \\
\text { months }\end{array}$ & $\begin{array}{c}\text { Mean } \\
\text { (treatments) }\end{array}$ \\
\hline K84/RD with K84 & & 207.00 & 7.00 & 0.00 & 329.33 & $135.83^{\mathrm{a}}$ \\
\hline UHFBA-212/RD with UHFBA-212 & & 269.67 & 5.33 & 0.00 & 285.33 & $140.08^{\mathrm{a}}$ \\
\hline C58/RD with C58 & & 127.33 & 4.00 & 23.00 & 37.33 & $47.92^{\mathrm{bc}}$ \\
\hline $\begin{array}{l}\text { Agrobacterium tumefaciens } \quad \mathrm{I}_{1} / \mathrm{RD} \quad \text { with } \\
\text { tumefaciens } \mathrm{I}_{1}\end{array}$ & Agrobacterium & 82.78 & 4.67 & 15.00 & 9.33 & $27.94^{\mathrm{c}}$ \\
\hline K84/RD with K84 and C58 & & 98.67 & 0.00 & 6.00 & 53.67 & $39.58^{\mathrm{bc}}$ \\
\hline C58/RD with K84 and C58 & & 143.31 & 6.33 & 0.00 & 64.00 & $53.41^{\mathrm{b}}$ \\
\hline $\begin{array}{l}\text { UHFBA-22/RD with } \text { UHFBA-212 and } \\
\text { tumefaciens } \mathrm{I}_{1}\end{array}$ & Agrobacterium & 145.00 & 5.00 & 0.00 & 83.33 & $58.33^{\mathrm{b}}$ \\
\hline $\begin{array}{l}\text { Agrobacterium tumefaciens } \mathrm{I}_{1} / \mathrm{RD} \text { with } \\
\text { Agrobacterium tumefaciens } \mathrm{I}_{1}\end{array}$ & UHFBA-212 and & 127.00 & 11.33 & 0.00 & 103.00 & $60.33^{\mathrm{b}}$ \\
\hline Control & & 0.00 & 0.00 & 0.00 & 0.00 & 0.00 \\
\hline Mean & & $133.42^{\mathrm{a}}$ & $4.85^{\mathrm{c}}$ & $4.89^{\mathrm{c}}$ & $107.26^{\mathrm{b}}$ & \\
\hline
\end{tabular}

Table 7. Colonization of Rhizobium radiobacter and Agrobacterium tumefaciens isolate(s) applied as seed treatment (ST) on bitter almond plants.

\begin{tabular}{|c|c|c|c|c|c|}
\hline \multirow{2}{*}{ Treatments } & \multicolumn{5}{|c|}{  } \\
\hline & $\begin{array}{c}\text { One } \\
\text { month }\end{array}$ & $\begin{array}{l}\text { Three } \\
\text { month }\end{array}$ & $\begin{array}{c}\text { Six } \\
\text { month }\end{array}$ & $\begin{array}{c}\text { Nine } \\
\text { Month }\end{array}$ & $\begin{array}{c}\text { Mean } \\
\text { (treatments) }\end{array}$ \\
\hline K84/ST with K84 & 130.33 & 4.67 & 0.00 & 311.33 & $111.58^{\mathrm{a}}$ \\
\hline UHFBA-212/ST with UHFBA-212 & 20.28 & 6.33 & 0.00 & 193.67 & $55.07^{\mathrm{c}}$ \\
\hline C58/ST with C58 & 76.67 & 3.67 & 17.00 & 92.67 & $47.50^{\mathrm{c}}$ \\
\hline $\begin{array}{l}\text { Agrobacterium } \quad \text { tumefaciens } \mathrm{I}_{1} / \mathrm{ST} \quad \text { with } \\
{\text { tumefaciens } \mathrm{I}_{1}}\end{array}$ & 121.33 & 3.00 & 16.00 & 159.00 & $74.83^{\mathrm{bc}}$ \\
\hline UHFBA-212/ST with UHFBA-212and C58 & 212.89 & 3.33 & 0.00 & 87.00 & $75.81^{\mathrm{bc}}$ \\
\hline C58/ST with UHFBA-212and C58 & 72.67 & 1.67 & 0.00 & 130.00 & $51.08^{\mathrm{c}}$ \\
\hline K84/ST with K 84 and Agrobacterium tumefaciens $\mathrm{I}_{1}$ & 198.67 & 3.00 & 0.00 & 158.00 & $89.92^{\mathrm{b}}$ \\
\hline $\begin{array}{l}\text { Agrobacterium tumefaciens } \mathrm{I}_{1} / \mathrm{ST} \text { with } \mathrm{K} 84 \text { and Agrobacterium } \\
\text { tumefaciens } \mathrm{I}_{1}\end{array}$ & 149.67 & 2.00 & 1.00 & 104.67 & $64.33^{b c}$ \\
\hline Control & 0.00 & 0.00 & 0.00 & 0.00 & 0.00 \\
\hline Mean (months) & $109.17^{\mathrm{b}}$ & $3.07^{\mathrm{c}}$ & $3.78^{\mathrm{c}}$ & $137.37^{\mathrm{a}}$ & \\
\hline
\end{tabular}

sults were also found by Kerr and Htay (1974), Raio et al. (1997) and Gupta et al. (2010) who reported that for a successful biological control, the population $R$. rhizogenes either must be of the same proportion or higher in number to that of $A$. tumefaciens.

Effect of native Rhizobium radiobacter isolate and Agrobacterium tumefaciens isolate on the incidence of crown gall: Maximum incidence (100\%) was observed on cherry rootstock Colt treated with A. tumefaciens $\mathrm{I}_{1}$ followed by C58 $(94.67 \%)$ on cherry rootstock Colt. Both the A. tumefaciens isolates viz., A. tumefaciens $\mathrm{I}_{1}$ and $\mathrm{C} 58$ showed incidence of $82.67 \%$ on plants raised from bitter almond seed, respectively. Minimum incidence (2\%) of disease was observed on bitter almond seed treated with UHFBA-212 and C58. Bitter almond seeds treated with Rhizobium rhizogenes strain K84 showed only 5 per cent incidence of crown gall compared to untreated (control) bitter almond plants raised from seed $(23.67 \%)$ and cherry rootstock Colt (13.33\%) (Table 8). When mutants of $R$. rhizogenes and A. tumefaciens were used in combina- tion the incidence of disease remained quite low compared to the treatments where only pathogenic mutants of A. tumefaciens were applied both as seed and root dip treatment. The study conducted on strain K84 by Canfield and Moore (1991), Moore et al. (1988) and Trembley et al. (1987) indicate that even in galled tissue large population sizes of both pathogenic agrobacteria and biocontrol agent K84 are maintained for several months, indicating that the potential of plasmid transfer between these bacteria exists under field conditions, this is why that incidence of crown gall was observed in each treatment and none of these treatments provide hundred per cent control of crown gall.

Phylogenetic analysis of $R$. rhizogenes strain UHFBA-212 (141/1A) by 16S rDNA sequence analysis: Rhizobium rhizogene strain UHFBA-212 (141/1A) was showing maximum rhizosphere competence and found to be the most effective biocontrol treatment against $A$. tumefaciens under field conditions, therefore strain UHFBA-212 was identified to the species level by $16 \mathrm{~S}$ rDNA sequence analysis. The $16 \mathrm{~S}$ rDNA fragment was 
Table 8. Effect of Rhizobium radiobacterco inoculated with Agrobacterium tumefaciensisolate (s) on the incidence of crown gall on bitter almond and cherry rootstock -Colt.

\begin{tabular}{lc}
\hline Treatments & Incidence of crown gall (\%) \\
\hline ST with K84 on bitter almond seeds & $5.00(12.78)^{*}$ \\
ST with UHFBA-212 on bitter almond seeds & $2.22(4.99)$ \\
RD with K84 on Colt & $9.33(17.71)$ \\
RD with UHFBA-212 on Colt & $2.67(7.69)$ \\
ST with C58on bitter almond seeds & $82.67(65.43)$ \\
ST with Agrobacterium tumefaciens $\mathrm{I}_{1}$ bitter almond seeds & $82.67(65.43)$ \\
RD with C58on Colt & $94.67(74.28)$ \\
RD with Agrobacterium tumefaciens $\mathrm{I}_{1}$ on Colt & $100.00(90.00)$ \\
RD with K84 and C58 on Colt & $9.33(17.71)$ \\
RD with UHFBA-212 and Agrobacterium tumefaciens $\mathrm{I}_{1}$ on Colt & $6.67(14.80)$ \\
ST with K 84 and Agrobacterium tumefaciens $\mathrm{I}_{1}$ onbitter almond seeds & $5.00(12.78)$ \\
ST with UHFBA-212 and C58on bitter almond seeds & $2.00(4.73)$ \\
Control (bitter almond seeds) & $23.67(27.71)$ \\
Control (Colt) & $13.33(21.20)$ \\
Mean & $31.37(26.56)$ \\
\hline
\end{tabular}

$\mathrm{CD}_{0.05}$ (Treatments) $=9.56 \mathrm{ST}=$ Seed treatment, $\mathrm{RD}=$ Root dip, *Figures in the parentheses are arc- sine transformed values.

successfully amplified using designed primers and sequenced. Both the forward and reverse sequences soobtained were corrected, and unreadable and ambiguous sequences were deleted. Based on nucleotides homology and phylogenetic analysis, the strain UHFBA-212 (141/1A) was detected to be Rhizobium sp. Nearest homolog was found to be Agrobacterium radiobacter (Fig. 3). Phenotypic comparisons of Agrobacterium spp. and Rhizobium spp. have subsequently been supported by phylogenetic inferences based on 16S rDNA sequence analyses (Farrand et al., 2003; Velazquez et al., 2010 and Mousavi et al., 2014).

\section{Conclusion}

Biological control is one of the indispensable approaches of integrated disease management. This study has shown the potential of Rhizobium rhizogenes strain UHFBA-212, as biocontrolagent against A. tumefaciens biovar 1 on bitter almond and cherry rootstock Colt. As far as we know, no comparative data concerning root colonization by the pathogen and the biocontrol agent have been obtained in situ in crown gall biocontrol experiments. Strain K84 has shown good rhizosphere colonization efficiency compared to the native strain UHFBA-212. In spite of the efficient biocontrol observed by strain K84 and UHFBA-212, average populations consisting of $10^{6}$ agrobacteria per $g$ of soil were found nine months after planting.Thus, these strains may be used as promising antagonists for the successful management of crown gall. However, the applicability of strain UHFBA-218 to other kinds of plants in the field should be investigated further.

\section{ACKNOWLEDGEMENTS}

The authors are highly thankful for the financial support received under the project "Molecular analysis of agrocin producing Agrobacterium radiobacter for bio- logical control of crown gall in stone fruits" from the National Fund for Basic, Strategic and Frontier Application Research in Agriculture, Indian Council of Agricultural Research, New Delhi.

\section{REFERENCES}

Bouzar, H., Daouzli, N., Krimi, Z., Alim, A. and Khemici, E. (1991). Crown gall incidence in plant nurseries of Algeria, characteristics of Agrobacterium tumefaciens strains, and biological control of strains sensitive and resistant to agrocine 84. Agronomie., 11: 901-908

Bruce, K.D., Hiorns, W.D., Hobman, J.L., Osborn, A.M., Strike, P. and Ritchie, D.A. (1992). Amplification of DNA from native populations of soil bacteria by using the polymerase chain reaction. Applied and Environmental Microbiology, 58:3413-3416

Bull, C.T., Weller, D.M. and Thomashow, L. S. (1991). Relationship between root colonization and suppression of Gaeumannomyces graminis var. tritici by Pseudomonas fluorescens strain 2-79. Phytopathology, 81:954-959

Canfield, M. L. and Moore, L. W. (1991). Isolation and characterization of opine utilizing strains of Agrobacterium tumefaciens and fluorescent strains of Pseudomonas spp. from rootstocks of Malus. Phytopathology, 81 (4):440-443

Conn, H. J. (1942). Validity of the genus Alcaligenes. Journal of Bacteriology, 44: 353-360

Costechareyre, D., Rhouma, A., Lavire, C., Portier, P., Chapulliot, D., Bertolla, F., Boubaker, A., Dessaux, Y. and Nesme, X. 2010. Rapid and efficient identification of Agrobacterium species by recA allele analysis. $M i-$ crobial Ecology, 60: 862-872

Escobar, M. A. and Dandekar, A. M. (2003). Agrobacterium tumefaciensas an agent of disease. Trends Plant Science., 8: 380-386

Farrand, S.K., van Berkum, P.B. and Oger, P. (2003). Agrobacterium is a definable genus of the family Rhizobiaceae. Int. J. Syst. Evol. Microbiol., 53, 1681-1687

Felsenstein, J. (1985). Confidence limits on phylogenies: an approach using the bootstrap. Evolution. 39: 783-791. 
doi: $10.2307 / 2408678$

Gross, D. C. (1988). Maximizing rhizosphere populations of fluorescent pseudomonads on potatoes and their effects on Erwiniacarotovora. Potato Association of America, 65: 697-710

Gupta, A. K., Kamal, B. and Khosla, K. (2005). Effect of fertilizers, soil amendments and antibacterial compounds on the incidence of crown gall on cherry rootstock colt. Journal of Mycology and Plant Pathology, 35(2): 286-288

Gupta, A. K., Khosla, K., Bhardwaj, S. S., Thakur, A., Devi, S., Jarial, R. S., Sharma, C., Singh, K. P., Srivastava, D. K. and Lal, R. (2010). Biological control of crown gall on peach and cherry rootstock Colt by native Agrobacterium radiobacter isolates. Open Horticulture Journal, 3: $1-10$

Haas, J. H., Moore, L. W., Ream, W. and Manulis, S. (1995). Universal PCR primers for detection of phytopathogenic Agrobacterium strains. Applied Environmental Microbiology,61: 2879- 2884

Jindal, K. K. and Sharma, R. C. (1988). Occurrence of biovar 1 of Agrobacterium tumefaciens on almond in India. Indian Phytopathology, 41(4): 614-615

Kapshuk, A. A. (1933). Bacteriological study of crown gall of fruit trees. In: Russian English Summary, Bull. N Caucasian Inst. for Plant Protection, Rostoff on Do., 2: 69-78

Kawaguchi, A., Inoue, K. and Ichinose, Y. (2008). Biological control of crown gall of grapevine, rose, and tomato by non-pathogenic Agrobacterium vitisstrain VAR03-1. Phytopathology, 98:1218-1225

Kawaguchi, A. (2013). Biological control of crown gall on grapevine and root colonization by nonpathogenicRhizobium vitisstrain ARK-1. Microbes and Environments, 28:306-311

Kawaguchi, A. (2014). Reduction of pathogen populations at grapevine wound sites is associated with the mechanism of biological control of crown gall by Rhizobium vitis strain ARK-1. Microbes and Environments, 29: 296302

Kawaguchi, A. (2015). Biological control agent Agrobacterium vitis strain ARK-1 suppresses expression of the virD2 and virE2 genes in tumorigenic A. vitis. European Journal of Plant Pathology. DOI 10.1007/s10658-0150730-8

Kerr, A. and Htay, K. (1974). Biological control of crown gall through bacteriocin production. Physiological Plant Pathology, 4: 37-44

Kerr, A. (1969). Transfer of virulence between isolates of Agrobacterium. Nature, 223: 1175-1176

Kerr, A. (1972). Biological control of crown gall: seed inoculation. Journal of Applied Bacteriology, 35: 493-497

Lindstrom, K. and Young, J.P.W. (2011). International Committee on Systematics of Prokaryotes Subcommittee on the taxonomy of Agrobacterium and Rhizobium. International Journal of Systematic and Evolutionary Microbiology, 61: 3089-3093

Loper, J. E., Haack, C. and Schroth, M. N. (1985). Population dynamics of soil pseudomonads in the rhizosphere of potato (Solanum tuberosum L.). Applied and Environmental Microbiology, 49: 416-422

Lippincott, B.B., Whatley, M.H. and Lippincott, J.A. (1977). Tumour induction by Agrobacterium involves attach- ment of the bacterium to a site on the host plant cell wall. Plant Physiology, 59: 388-90

Moore, L.W. and Allen, J. (1977). Comparison of selective and differential media for Agrobacterium species. Proceedings of American Phytopathological Society, 4: 209

Moore L W and Canfield M. 1996. Biology of Agrobacterium and management of crown gall disease. In: Hall $\mathrm{R}$ (Ed.), Principles and practices of managing soil borne plant pathogens. Ontario, USA: APS Press, pp. 151-191

Moore, L. W., Kado, C. I. and Bouzar, H. (1988). Gram negative bacteria -Agrobacterium .In: Laboratory guide for identification for pathogenic bacteria $2^{\text {nd }} e d n$, Schaad N W (ed.), The American Phytopathological Society, St. Paul, Minnesota, pp. 16-36

Mousavi, S. A., Osterman, J., Wahlberg, N., Nesme, X., Lavire, C., Vial, L., Paulin, L., Lajudie, P. De. and Lindstrom, K. (2014). Phylogeny of the RhizobiumAllorhizobium-Agrobacterium clade supports the delineation of Neorhizobium gen. nov.Systematic and Applied Microbiolgy, 37: 208-215

Murugesan, S., Manoharan, C., Vijayakumar, R. and Panneerselvam, A. 2010. Isolation and characterization of Agrobacterium rhizogenesfrom the root nodules of some leguminous plants. International Journal of Microbiological Research, 1(3): 92-96

New, P. B. and Kerr. (1972). Biological control of crown gall: field measurements and glasshouse experiments. Journal of Applied Bacteriology, 35(2): 279-287

Penalver, R. and Lopez, M. M. (1999). Co-colonization of the rhizosphere by pathogenic strains K-84 and K-1026, used for crown gall bio-control. Applied and Environmental Microbiology, 65: 1936-1940

Pulawska, J. (2010). Crown gall of stone fruits and nuts, economic significance and diversity of its causal agents: tumorigenic Agrobacterium spp. Journal of Plant Pathology, 92(1): 87-98

Raio, A., Zoina, A. and Moore, L. W. (1997). The effect of solar heating of soil on natural and inoculated agrobacteria. Plant Pathology, 46: 320-328

Raio, A., Peluso, R., Puopolo, G. and Zoina, A. (2009). Evidence of pAgK84 transfer from Agrobacterium rhizogenes K84 to natural pathogenic Agrobacterium spp. in an Italian peach nursery. Plant Pathology, 58:745-753

Sawada, H., Ieki, H., Oyaizu, H. and Matsumoto, S. (1993). Proposal for rejection of Agrobacterium tumefaciens and revised descriptions for the genus Agrobacterium and for Agrobacterium radiobacter and Agrobacterium rhizogenes. Int J SystBacteriol., 43: 694-702

Smith, E. F. and Townsend, C. O. (1907). A plant tumour of bacterial origin. Science, 25:671- 673

Stockwell, V.O., Kawalek, M.D., Moore, L.W. and Lopper, J.E. (1996). Transfer of pAgK84 from the biocontrol agent Agrobacterium radiobacter $\mathrm{K} 84$ to A. tumefaciens under field conditions. Phytopathology, 86:31-7.

Thakur, D., Yadav A., Gogoi B. K. and Bora, T.C. (2007). Isolation and screening of Streptomyces in soil of protected forest areas from the states of Assam and Tripura, India, for antimicrobial metabolites. Journal of Medical Mycology, 17: 242-249

Trembley, G., Lambert, R., Lebeuf, H. and Dion, P. (1987). Isolation of bacteria from soil and crown-gall tumors on the basis of their capacity for opine utilization. Phyto- 
protection, 68:35-42.

Velazquez, E., Palomo, J. L., Rivas, R., Guerra, H., Peix, A., Trujillo, M. E., Garcı'a-Benavides, P., Mateos, P. F., Wabiko, H. and Martınez- Molina, E. (2010). Analysis of core genes supports the reclassification of strains Agrobacterium radiobacter $\mathrm{K} 84$ and Agrobacterium tumefaciens AKE10 into the species Rhizobium rhizogenes. Syst. Appl. Microbiol., 33: 247-251

Vicedo, B., Penlaver, R., Asins, M. J. and Lopez, M. M. (1993). Biological control of Agrobacterium tumefaciens, colonization, and pAGK84 transfer of the Ti plasmid of Agrobacterium radiobacter $\mathrm{K} 84$ and the Tra -mutant strain K1026. Applied and Environmental Microbiology, 59: 309-315
Wang, H.M., H.X. Wang, T.B. Ng, and J.Y. Li. (2003). Purification and characterization of an antibacterial compound produced byAgrobacterium vitis strain E26 with activity against A. tumefaciens. Plant Pathology, 52:134-143

Young, J. M., Kuykendall, L. D., Martinez-Romero, E., Kerr, A. and Sawada, H. (2001). A revision of Rhizobium Frank 1889, with and emended description of the genus, and the inclusion of all species of Agrobacterium Conn. 1942 and Allorhizobium undicola de Lajudie et al. 1989 as new combinations: Rhizobium radiobacter, $R$. rhizogene, R. Rubi and R. vitis. International journal of Systematic and Evolutionary Microbiology, 51: 89-103

Zambryski, P.C. (1998). Basic processes underlying Agrobacterium-mediated DNA transfer to plant cells. Ann. Rev. Genet., 22: 1-33 